\title{
Vascular-related NAC-domain 7 directly regulates a broad range of genes for xylem vessel differentiation
}

\author{
Masatoshi Yamaguchi ${ }^{*}$, Nobutaka Mitsuda ${ }^{2}$, Misato Ohtani ${ }^{3}$, Masaru Ohme-Takagi ${ }^{2}$, Ko Kato $^{1}$, Taku Demura ${ }^{4}$ \\ From IUFRO Tree Biotechnology Conference 2011: From Genomes to Integration and Delivery \\ Arraial d'Ajuda, Bahia, Brazil. 26 June - 2 July 2011
}

\section{Background}

Xylem functions in conduction of water and minerals throughout the plants, and supports the plant body. One of the features of xylem cells is development of secondary wall structure between plasma membrane and (primary) cell wall. Recently, it is expected that knowledge on xylem development can be utilized for application of improvement of the plant biomass, since most portion of wood, which represents one of important sources of woody biomass, is mainly composed of two types of xylem cells, xylem vessels and fiber cells.

Previously we established the in vitro transdifferentiation system, in which Arabidopsis suspension cells could synchronously transdifferentiate into xylem vessel elements. A number of genes whose expression is elevated during the transdifferentiation processes have been isolated by using microarray analysis [1]. We revealed that one of the identified genes, which encoded a NAC domain protein, VND7 (Vascular-Related NAC Domain Protein7), plays a pivotal role in promoting the xylem vessel differentiation $[1,2]$.

Recently, to efficiently obtain xylem vessel elements, we used a glucocorticoid-mediated post-translational induction system [3]. The transgenic Arabidopsis plants exhibited transdifferentiation of most of cells into xylem vessel elements, and the plants died. This induction system worked in poplar trees and in suspension cultures of cells from Arabidopsis and tobacco. These data demonstrate that the induction systems controlling VND7 activity can be used as powerful tools for understanding xylem cell differentiation.

\footnotetext{
* Correspondence: yamagu@bs.naist.jp

${ }^{1}$ Graduate School of Bioscience, NARA Institute of Science and Technology, Japan

Full list of author information is available at the end of the article
}

\section{Objectives of the research}

Several studies report that VND7 regulates expression of downstream of some transcription factors, suggesting that existence of transcriptional network regulating xylem vessel differentiation. Here, in order to identify direct target genes of VND7, we performed global transcriptome analysis using Arabidopsis transgenic lines in which VND7 activity could be induced posttranslationally.

\section{Methods}

We generated a transgenic Arabidopsis plant expressing VND7-VP16-GR[3] driven by CaMV35S promoter. VND7-VP16-GR and VP16-GR seedlings were soaked with water containing $10 \mu \mathrm{M}$ cycloheximide (CHX), a protein synthesis inhibitor, for 2 hours. After removal of the solution, the seedlings were re-soaked with water containing $10 \mu \mathrm{M} \mathrm{CHX}$, with or without $10 \mu \mathrm{M}$ dexamethazone (DEX), for 4 hours. Microarray analysis was performed using GeneChip ATH1 Arabidopsis genome arrays. The effector, reporter, and reference plasmids [4], were delivered into the rosette leaves of Arabidopsis by particle bombardment. After overnight incubation, luciferase activity was assayed. For electrophoretic mobility shift assay (EMSA), promoter fragments were labeled with biotin. The poly-His-tagged $\mathrm{N}$-terminal region of VND7 (His-VND7 ${ }^{1-161}$ ) protein was purified from Escherichia coli.

\section{Results}

As shown previously, overexpression of $V N D 7$ induces expression of many genes related to the differentiation of vascular vessels [4]. Microarray analysis revealed that 300 genes are upregulated by more than two-fold in the transgenic VND7 plant. To identify direct target genes 
of VND7 among the upregulated genes, we used a glucocorticoid-mediated posttranslational induction system. We generated a transgenic Arabidopsis plant expressing chimera VND7-VP16-GR gene under the control of the CaMV35S promoter [3]. We subjected VND7-VP16-GR seedlings to pre-treatment with $\mathrm{CHX}$, followed by treatment with or without DEX. Microarray analysis using these samples revealed that, among the 300 genes upregulated in the VND7-YFP plants, 63 were also upregulated (fold change $>2$; FDR $<0.1[P<0.026]$ ) in the VND7-VP16-GR plants in response to DEX treatment. These genes encode a broad range of proteins such as transcription factors, IRREGULAR XYLEM proteins, and proteolytic enzymes, known to be closely associated with xylem vessel formation [5].

To define the promoter region responsible for the upregulation of gene expression by VND7, we carried out transient reporter assays using the $X C P 1$ promoter sequence. We constructed reporter plasmids by linking various lengths of $X C P 1$ promoter sequences to a minimal CaMV $35 S$ promoter driving the firefly luciferase gene and the VND7 gene driven by CaMV $35 S$ promoter was used as an effector plasmid. We concluded that the region of $X C P 1$ promoter between residues -211 and -96 is necessary and sufficient for gene expression induced by VND7 [5].

In order to investigate the direct DNA/protein interaction between the $X C P 1$ promoter sequence and the VND7 protein, we carried out EMSA. Two distinct regions of the $X C P 1$ promoter were demonstrated to be responsible for VND7 binding. Furthermore, we also showed that VND7 protein binds to several promoter sequences present in candidate direct target genes [5].

\section{Conclusions}

These findings indicated that VND7 upregulates, directly and/or indirectly, many genes involved in a wide range of processes in xylem vessel differentiation. Interestingly, VND7 directly regulates lots of genes involved in programmed cell death, while most of genes controlling secondary cell wall biosynthesis could be regulated through the MYB transcription factors. Further investigation of consensus DNA binding sequences of target genes will help elucidate the regulation of gene expression in xylem vessel formation. To obtain a view of xylem vessel differentiation, we also need to reveal how the direct target genes function during xylem vessel formation.

\section{Author details}

${ }^{1}$ Graduate School of Bioscience, NARA Institute of Science and Technology, Japan. ${ }^{2}$ National Institute of Advanced Industrial Science and Technology, Japan. ${ }^{3}$ RIKEN Biomass Engineering Program, Japan. ${ }^{4}$ Graduate School of
Bioscience, NARA Institute of Science Technology, Japan and RIKEN Biomass Engineering Program, Japan.

Published: 13 September 2011

References

1. Kubo M, Udagawa M, Nishikubo N, Horiguchi G, Yamaguchi M, Ito J, Mimura T, Fukuda H, Demura T: Transcription switches for protoxylem and metaxylem vessel formation. Genes Dev 2005, 19:1855-1860.

2. Yamaguchi $M$, Kubo $M$, Fukuda $H$, Demura T: VASCULAR-RELATED NACDOMAIN7 is involved in the differentiation of all types of xylem vessels in Arabidopsis roots and shoots. Plant J 2008, 55:652-664.

3. Yamaguchi M, Goué N, Igarashi H, Ohtani M, Nakano Y, Mortimer JC, Nishikubo N, Kubo M, Katayama Y, Kakegawa K, Dupree P, Demura T: VASCULAR-RELATED NAC-DOMAIN6 and VASCULAR-RELATED NACDOMAIN7 effectively induce transdifferentiation into xylem vessel elements uder control of an induction system. Plant Physiol 2010, 153:906-914.

4. Yamaguchi M, Ohtani M, Mitsuda N, Kubo M, Ohme-Takagi M, Fukuda H, Demura T: VND-INTERACTING2, a NAC domain transcription factor negatively regulates xylem vessel formation in Arabidopsis. Plant Cell 2010, 22:1249-1263.

5. Yamaguchi M, Mitsuda N, Ohtani M, Ohme-Takagi M, Kato K, Demura T: VASCULAR-RELATED NAC-DOMAIN 7 directly regulates the expression of a broad range of genes for xylem vessel formation. Plant J 2011, 66:579-590.

doi:10.1186/1753-6561-5-S7-037

Cite this article as: Yamaguchi et al:: Vascular-related NAC-domain 7 directly regulates a broad range of genes for xylem vessel differentiation. BMC Proceedings 2011 5(Suppl 7):O37.

\section{Submit your next manuscript to BioMed Central} and take full advantage of:

- Convenient online submission

- Thorough peer review

- No space constraints or color figure charges

- Immediate publication on acceptance

- Inclusion in PubMed, CAS, Scopus and Google Scholar

- Research which is freely available for redistribution

Submit your manuscript at www.biomedcentral.com/submit
Ciomed Central 